Clin Epidemiol 2001; 54: 634-44.

13. Kaukua J, Turpeinen A, Uusitupa M, Niskanen L. Clustering of cardiovascular risk factors in type 2 diabetes mellitus: prognostic significance and tracking. Diabetes, Obes Metab 2001; 3: 17-23.

14. Yusuf HR, Giles WH, Croft JB, Anda RF, Casper ML. Impact of multiple risk factor profiles on determining cardiovascular disease risk. Prev Med 1998; 27: 1-9.

15. Urbina EM, Srinivasan SR, Tang R, Bond MG, Kieltyka L, Berenson GS. Impact of multiple coronary risk factors on the intima-media thickness of different segments of carotid artery in healthy young adults (The Bogalusa Heart Study). Am J Cardiol 2002; 90: 953-58.

16. Fine LJ, Philogene GS, Gramling R, Coups EJ, Sinha S. Prevalence of multiple chronic disease risk factors. 2001 National Health Interview Survey. Am J Prev Med 2004; 27 (Suppl 2): 18-24.
17. Kim S, Popkin BM, Siega-Riz AM, Haines PS, Arab L. A cross-national comparison of lifestyle between China and the United States, using a comprehensive cross-national measurement tool of the healthfulness of lifestyles: the Lifestyle Index. Prev Med 2004; 38: 160-71.

18. Mathers C, Vos T, Stevenson C. The burden of disease and injury in Australia. Australian Institute of Health and Welfare cat. No PHE 17, Canberra: AIHW, 1999

19. Miller Y. Development of a chronic disease risk factor index in the NSW Health Survey Program. Report No: CPAH 03-0008. Sydney. NSW Centre for Physical Activity and Health, 2003.

20. Australian Bureau of Statistics. Socioeconomic indexes for areas, Australia 2001. ABS Catalogue no. 2039.0. Canberra: ABS, 2003.

21. Australian Bureau of Statistics. National Health Survey: Summary of results. ABS Cat. No. 4364.0. Canberra: ABS, 2002. 좀

\title{
ADMISSION TO HOSPITAL FOR SUNBURN AND DRUG PHOTOTOXIC AND PHOTOALLERGIC RESPONSES: NEW SOUTH WALES, 1993-94 TO 2000-01
}

\section{Paul Beggs}

Department of Physical Geography

Macquarie University

This article describes the incidence of patients with sunburn and drug-induced phototoxic and photoallergic response who have required hospitalisation in NSW between 1993-94 and 2000-01.

\section{BACKGROUND}

High levels of ultraviolet (UV) radiation in Australia, and the fair-skinned nature of a large portion of its population, make sunburn and its long-term consequences a major public health issue in this country. Despite this, there have been few studies of the incidence of sunburn in Australia. A recent survey of men from northern Australia with a history of non-melanoma skin cancer found that over half reported recent sunburn. ${ }^{1}$ Considerable attention has been given to the study of sun protection knowledge, attitudes, behaviour, exposure, and education programs in Australia, particularly in school children ${ }^{2-5}$ and young adults. ${ }^{6}$

Photosensitivity refers to an abnormal cutaneous response involving the interaction between photosensitising substances (including many medications) and UV radiation. Medication-induced photosensitivity also has the potential to be a significant public health concern, having the potential to increase the incidence of skin cancer. ${ }^{7}$ While Moore ${ }^{7}$ has recently reviewed many aspects of drug-induced cutaneous photosensitivity, and Beggs ${ }^{8}$ has raised the potential consequences of stratospheric ozone depletion for photosensitivity, the issue has been somewhat neglected in Australia. For example, Moore ${ }^{7}$ has noted the remarkably infrequent summaries on the subject of drug-induced photosensitivity from the Adverse Drug Reactions Advisory Committee of the Australian Therapeutic Goods Administration, the most recent being in $1983^{9}$ and $1987 .{ }^{10}$

This study examined routinely collected data to determine both the incidence of sunburn and drug-induced phototoxic and photoallergic response requiring hospitalisation in NSW, and the characteristics of these patients.

\section{METHODS}

Data used in this study were from NSW Health's Inpatient Statistics Collection (ISC). Eight years of de-identified unit record data were obtained, from 1 July 1993 to 30 June 2001. Clinical information in the Inpatient Statistics Collection, such as principal diagnosis, additional diagnoses, and external causes of injury or poisoning, are coded according to the International Statistical Classification of Diseases and Related Health Problems - Tenth Revision - Australian Modification (ICD-10-AM). Codes examined included L55 (sunburn), including L55.0 (sunburn, erythema), L55.1 (sunburn, partial thickness), L55.2 (sunburn, full thickness), L55.8 (other sunburn), and L55.9 (sunburn, unspecified); and L56 (other acute skin changes due to ultraviolet radiation), including L56.0 (drug phototoxic response) and L56.1 (drug photoallergic response). External causes Y40-Y59 (drugs, medicaments and biological substances causing adverse effects in therapeutic use) used in addition to the two L56 codes were also examined in 
order to identify the associated drug. ICD-9-CM was used prior to the introduction of ICD-10-AM in 1998-99. The L55 diagnoses had been mapped from 692.71 (sunburn); the L56 diagnoses from 692.72 (acute dermatitis due to solar radiation); and Y40-Y59 from E930-E949 (drugs, medicinal and biological substances causing adverse effects in therapeutic use).

Temporal characteristics were examined by analysis of the data by year, month, and day of the week. Spatial characteristics were examined by analysis of the data by statistical division, and latitudinal (north or south) and coastal/non-coastal groupings of statistical divisions. Incidence rates were calculated using 1996 census populations. Rates were age-standardised using the 1996 Australian population.

\section{RESULTS}

The number of admissions for sunburn as either the principal or as additional diagnoses was small, with a total of 508 over the study period (Table 1). Most of these
(58 per cent) were as principal diagnosis. In order to focus on admissions where sunburn was chiefly responsible, all sunburn results presented hereafter are for the principal diagnoses admissions only. The average annual statewide age-standardised incidence rate for sunburn was 0.58 per person year per 100,000. Overall, more females were admitted with sunburn: a male to female ratio of 0.8:1. However, more males than females were admitted between the ages of five and 14 (Table 2). The median age of admissions with sunburn was 22; the range was from less than one year of age to 95 years of age. The under five years age group had over twice as many admissions as any other age group, and admissions for children under one year of age occurred in every year. The majority of sunburn admissions (83 per cent) were born in Australia, followed by England, New Zealand, and Ireland (each with about two per cent).

Of the 293 sunburn admissions, 131 (45 per cent) had one or more additional diagnoses. Although 125 codes were used as additional diagnosis, 'burns classified according

\section{TABLE 1}

SUMMARY OF ADMISSIONS FOR SUNBURN (L55)^ IN NSW FROM 1993-94 TO 2000-01

\begin{tabular}{|c|c|c|c|c|c|}
\hline Year & $\begin{array}{c}\text { Principal } \\
\text { diagnosis } \\
n\end{array}$ & $\begin{array}{c}\text { Additional } \\
\text { diagnosis }^{b} \\
n\end{array}$ & $\begin{array}{c}\text { Total } \\
n \\
\end{array}$ & $\begin{array}{c}\text { Crude rate per } 100,000 \\
\text { person years }^{a}\end{array}$ & $\begin{array}{c}\text { Age-standardised rate } \\
\text { per } 100,000 \text { person years }\end{array}$ \\
\hline 1993-94 & 14 & 10 & 24 & 0.23 & 0.23 \\
\hline 1994-95 & 23 & 11 & 34 & 0.38 & 0.38 \\
\hline 1995-96 & 23 & 12 & 35 & 0.38 & 0.33 \\
\hline 1996-97 & 32 & 26 & 58 & 0.53 & 0.52 \\
\hline 1997-98 & 25 & 38 & 63 & 0.41 & 0.40 \\
\hline 1998-99 & 76 & 38 & 114 & 1.26 & 1.21 \\
\hline 1999-00 & 51 & 43 & 94 & 0.84 & 0.83 \\
\hline 2000-01 & 49 & 37 & 86 & 0.81 & 0.75 \\
\hline Total & 293 & 215 & 508 & 0.61 & 0.58 \\
\hline \multicolumn{6}{|c|}{ `L55 includes sunburn, erythema; sunburn, partial thickness; sunburn, full thickness; other sunburn; and sunburn, unspecified. } \\
\hline Note: & \multicolumn{5}{|c|}{$\begin{array}{l}\text { a these relate only to principal diagnosis. } \\
\text { b additional diagnoses of sunburn where sunburn was also the principal diagnosis are excluded. }\end{array}$} \\
\hline Source: & \multicolumn{5}{|c|}{ NSW Health Inpatient Statistics Collection } \\
\hline
\end{tabular}

\section{TABLE 2}

AVERAGE ANNUAL HOSPITAL SEPARATION RATES (PER 100,000) FOR SUNBURN BY AGE GROUP AND GENDER, NSW, 1993-94 TO 2000-01

\begin{tabular}{|lccc|}
\hline Age (years) & Males & Females & Total \\
\hline $0-4$ & 1.60 & 1.98 & 0.42 \\
$5-9$ & 1.08 & 0.30 & 0.76 \\
$10-14$ & 1.14 & 0.87 & 0.73 \\
$15-19$ & 0.65 & 0.81 & 0.76 \\
$20-24$ & 0.17 & 0.50 & 0.49 \\
$25-29$ & 0.62 & 0.69 & 0.53 \\
$30-34$ & 0.37 & 0.67 & 0.52 \\
$35-39$ & 0.37 & 0.45 & 0.28 \\
$40-44$ & 0.11 & 0.78 & 0.48 \\
$45-49$ & 0.18 & 0.76 & 0.53 \\
$50-54$ & 0.30 & 1.11 & 0.77 \\
$55-59$ & 0.45 & 0.73 & 0.47 \\
$60-64$ & 0.21 & 0.17 & 0.21 \\
$65+$ & 0.27 & $\mathbf{0 . 6 8}$ & 0.61 \\
\hline Total & $\mathbf{0 . 5 4}$ & & \\
\hline Source: NSW Health Inpatient Statistics Collection & & \\
\hline
\end{tabular}


to extent of body surface involved' (T31) made up 22 per cent of additional diagnoses, with the next most common being 'volume depletion' (E86) with six per cent. Only 77 (26 per cent) of the sunburn records included an external cause of injury or poisoning code, with the most common of these being exposure to sunlight (X32).

The number of sunburn admissions varied from year to year, with the lowest number, 14, in 1993-94 compared to 76 in 1998-99. There was a distinctive seasonal distribution (Figure 1), with most admissions occurring in November to February inclusive, and particularly high rates in December and January (25 per cent and 28 per cent respectively). Admissions also varied according to the day of the week, with 25 per cent occurring on Tuesdays and 17 per cent on Mondays and Thursdays. The western (non-coastal) statistical divisions appeared to have the highest rates, with the overall average annual age-standardised incidence rate of these being 0.82 per person year per 100,000 compared to 0.54 per person year per 100,000 for the eastern (coastal) statistical divisions. A much smaller difference was seen in northern versus southern statistical divisions (age-standardised incidence rates of 0.64 and 0.57 per person year per 100,000 respectively).

There were no admissions for drug phototoxic response, and admissions for drug photoallergic response occurred in only two years, 1998-99 and 1999-00, with less than five cases in each year. External causes of these few cases included tetracyclines (systematic antibiotics) (Y40.4), other systemic antibiotics (Y40.8), iminostilbenes (Carbamazepine, an antiepileptic) (Y46.4), and unspecified drug or medicament (Y57.9).

\section{DISCUSSION}

The NSW Inpatient Statistics Collection (ISC) is the most reliable measure of illness that can be readily obtained from official sources. It is a 'census of all admitted patient services provided by New South Wales Public Hospitals, Public Psychiatric Hospitals, Public Multi-Purpose Services, Private Hospitals, and Private Day Procedures Centres'. ${ }^{11}$ Therefore, one of its limitations is that it does not capture patients who present only to emergency departments, general practices or other non-hospital health services (such as pharmacies), or those who do not consult any health service. Errors that have been identified for the ISC include non-response (failure to collect all relevant data), errors in transcribing patient data from medical records to the collection media, coding errors, and clerical and editing errors. It is also noteworthy that the reliability of ISC data depends on the specific disease, and that there is likely to be variability in hospital admission practices.

The overall predominance of females admitted for sunburn is consistent with studies of adolescents in NSW showing a lower prevalence of adequate sun protection in females compared to males, and gender being a significant predictor of having an adequate level of sun protection. $^{2}$ The concentration of admissions in younger age groups is a concern, given that sunburn in children and adolescents may play an important role in the development of melanoma. ${ }^{2,3}$

Although the cause of the peak in sunburn admissions in 1998-99 is unlikely to be simple, it is noteworthy that the area of the Southern Hemisphere stratospheric ozone hole (where the total ozone amount is less than 220 Dobson units) was particularly large in the spring and summer of 1998, existing for longer (to 15 December) than in any other year recorded and almost reaching its maximum size (around 27 million $\mathrm{km}^{2}$ ). ${ }^{12}$ The introduction of ICD-10-AM in 1998-99 may have also contributed to the big increase in separations in this year. In other similar studies ${ }^{13}$, it has been suggested that such an increase could reflect improvements in recording of hospital data.

The peak in sunburn admissions over the summer months was expected given the peak in UV radiation and outdoor activity at this time of the year. Although more sunburn admissions were expected on the weekend, the finding of more during the week (particularly Tuesday) may have resulted from individuals with severe sunburn waiting a day or more after exposure on the weekend before seeking help.

The drugs identified as external causes of the few photoallergic responses (tetracyclines, other antibiotics, and carbamazepine) are known to potentially cause adverse photosensitivity reactions. ${ }^{14}$

This work could be expanded to consider other Australian states and territories as well as other countries. This study has only examined severe cases of sunburn and drug phototoxic and photoallergic response, those requiring hospitalisation. Further study is required of the incidence and characteristics of less severe sunburn and drug phototoxic and photoallergic responses in Australia. Such work could examine measures such as hospital attendance, general practitioner visit, or a specifically designed survey. Such a study has produced interesting results in Southern Chile ${ }^{15}$, with analysis of dermatologists' records of sunburns and photosensitivity disorders revealing a significant increase associated with stratospheric ozone depletion and increased ground level UVB radiation. More importantly, the long-term implications of these responses require consideration in Australia, with the examination of past medical records (including medication use) of skin cancer patients one method likely to provide answers to this important question.

\section{CONCLUSION}

The results of this study suggest that hospitalisation for sunburn and drug phototoxic and photoallergic responses, in itself, is not a major public health issue in NSW. However, some of the trends revealed in this study should be noted by sun protection program developers, and the long-term implications of these severe sunburn cases are a concern. The incidence of less-severe sunburn and photosensitivity responses remains inadequately quantified at present. 


\section{FIGURE 1}

MONTH OF ADMISSION FOR SUNBURN (L55)* IN NEW SOUTH WALES FROM 1 JULY 1993 TO 30 JUNE 2001. ONLY PRINCIPAL DIAGNOSIS SUNBURN ADMISSIONS ARE SHOWN

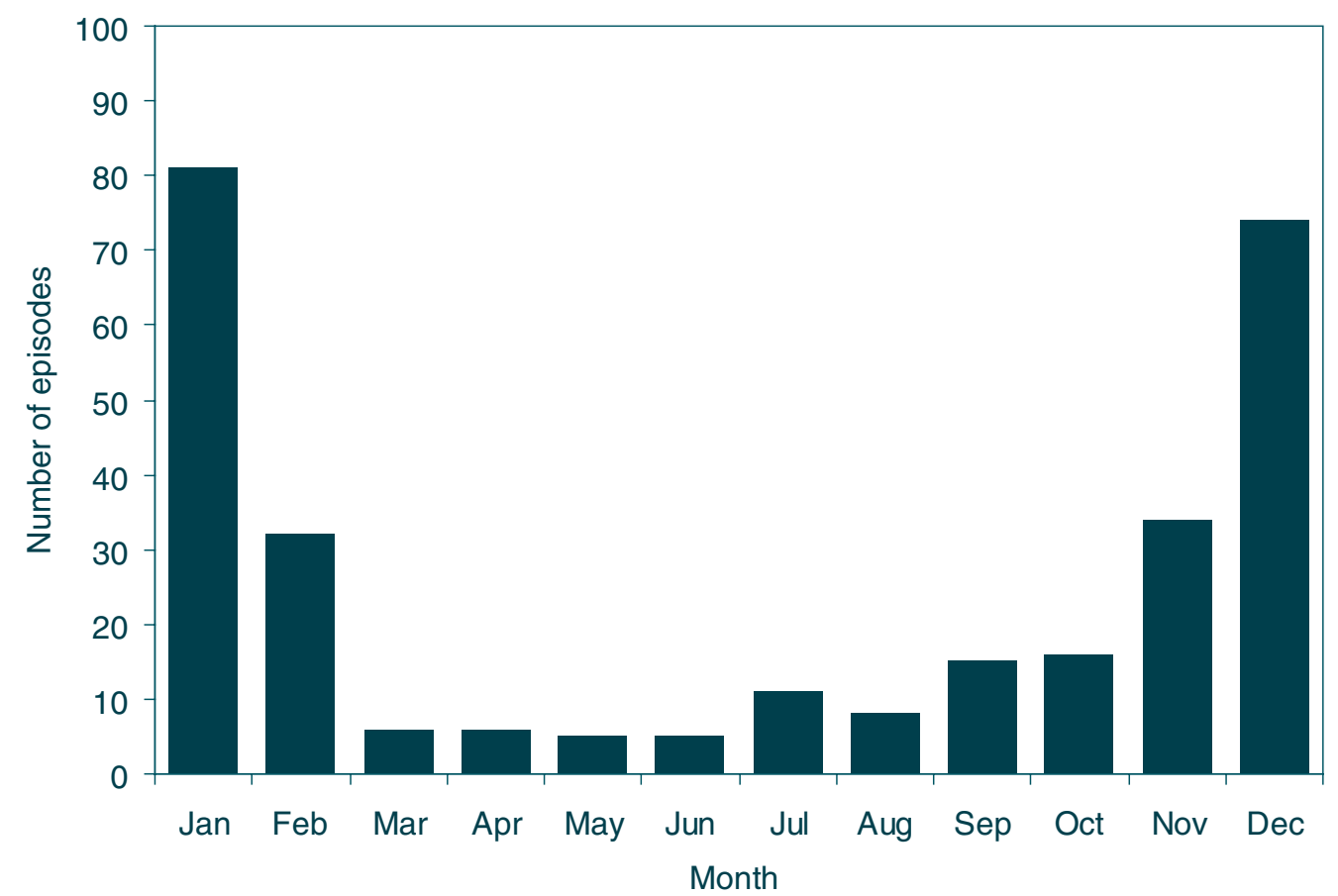

* L55 includes sunburn, erythema; sunburn, partial thickness; sunburn, full thickness; other sunburn; and sunburn, unspecified.

Source: NSW Health Inpatient Statistics Collection.

\section{ACKNOWLEDGMENTS}

The assistance of Frank Siciliano is gratefully acknowledged. I also thank John Agland (Manager, Information Analysis and Dissemination Unit, NSW Health) for assistance with access to the ISC.

\section{REFERENCES}

1. Woolley T, Buettner PG, Lowe JB. Sunburn in Australian men with a history of non-melanoma skin cancer. Am J Health Behav 2003; 27(3): 195-207.

2. Lower T, Girgis A, Sanson-Fisher R. The prevalence and predictors of solar protection use among adolescents. Prev Med 1998; 27(3): 391-9.

3. Lowe, JB, Borland R, Stanton WR, Baade P, et al. Sun-safe behaviour among secondary school students in Australia. Health Educ Res 2000; 15(3): 271-81.

4. Milne, E, English DR, Johnston R, Cross D, et al. Improved sun protection behaviour in children after two years of the Kidskin intervention. Aust N Z J Public Health 2000; 24(5): 481-7.

5. Livingston PM, White VM, Ugoni AM, Borland R. Knowledge, attitudes and self-care practices related to sun protection among secondary students in Australia. Health Educ Res 2001; 16(3): 269-78.

6. Schofield PE, Freeman JL, Dixon HG, Borland R, et al. Trends in sun protection behaviour among Australian young adults. Aust N Z J Public Health 2001; 25(1): 62-5.

7. Moore DE. Drug-induced cutaneous photosensitivity: incidence, mechanism, prevention and management. Drug Saf 2002; 25(5): 345-72.

8. Beggs PJ. Impacts of climate and climate change on medications and human health. Aust N Z J Public Health 2000; 24(6): 630-2.

9. Adverse Drug Reactions Advisory Committee (ADRAC). Photosensitivity reactions: a sunburnt country. Aust Adverse Drug React Bull 1983; March.

10. Adverse Drug Reactions Advisory Committee (ADRAC). A sunburnt country revisited. Aust Adverse Drug React Bull 1987; Feb: 2-3.

11. NSW Department of Health. NSW Health data collections: Inpatient statistics collection. At www.health.nsw.gov.au/im/ ims/isc/index.html; page last updated 23 December 2003 and accessed 24 January 2005.

12. Climate Prediction Center. Stratosphere: Southern Hemisphere ozone hole size. National Weather Service, National Oceanic and Atmospheric Administration. At www.cpc.ncep.noaa. gov/products/stratosphere/sbuv2to/ozone_hole.html; page last modified 15 August 2002 and accessed 20 January 2004.

13. Jorm L. Firework injuries in New South Wales, 1992-93 to 2001-02. N S W Public Health Bull 2003; 14(6): 110-3.

14. MIMS Australia. 2001 MIMS annual. Australian edition. Twenty-fifth edition. Sydney: MIMS Australia; 2001.

15. Abarca JF, Casiccia CC, Zamorano FD. Increase in sunburns and photosensitivity disorders at the edge of the Antarctic ozone hole, Southern Chile, 1986-2000. J Am Acad Dermatol 2002; 46(2): 193-9. 